\title{
Relationship between electrocardiographic characteristics of left bundle branch block and echocardiographic findings
}

\author{
Augusto J. Lépori, Ricardo S. Mishima, Gonzalo Rodríguez, \\ Eduardo A. Moreyra, Jose L. Serra, Miguel A. Tibaldi, \\ Andres Martellotto, Eduardo Moreyra Jr. \\ Cardiology Division, Sanatorio Allende, Córdoba, Argentina
}

\begin{abstract}
Background: Complete left bundle branch block (CLBBB) is an electrocardiographic (ECG) dromotropic disorder seen in patients with various structural heart diseases and sometimes is associated with poor prognosis. Its presence confounds the application of standard ECG criteria for the diagnosis of left ventricular hypertrophy (LVH), myocardial infarction (MI) in the chronic phase, and pathologies that produce changes on ST-T segment. The aim of this investigation was to establish the relationship between CLBBB and cardiac structural abnormalities assessed by echocardiography.
\end{abstract}

Methods: This observational, cross-sectional study included ECG with CLBBB from 101 patients who also had transthoracic echocardiogram (TTE) performed within 6 months.

Results: The prevalence of structural heart disease on TTE was 90\%. No ECG criterion was useful to diagnose LVH since no relationship was observed between 9 different ECG signs and increased left ventricular mass index. QRS duration $(p=0.16)$ and left axis deviation $(p=0.09)$ were unrelated to reduced left ventricular ejection fraction (LVEF). Eight ECG signs proposed for the diagnosis of the chronic phase of MI demonstrated similar effectiveness, with high specificity and reduced sensitivity.

Conclusions: $C L B B B$ is associated with elevated prevalence of cardiac structural disease and hinders the application of common ECG criteria for the diagnosis of LVH, reduced LVEF, or chronic phase of MI. No ECG finding distinguished patients with structural heart disease from those with normal hearts. Electrocardiographic criteria for the diagnosis of MI in the chronic phase are useful when present, but when absent cannot rule it out. (Cardiol J 2015; 22, 4: 397-403)

Key words: complete left bundle branch block, transthoracic echocardiogram, left ventricular hypertrophy, chronic phase of myocardial infarction

\section{Introduction}

Complete left bundle branch block (CLBBB) is a dromotropic disorder that occurs as a result of interruption or slowing conduction in (1) the left His bundle, (2) the stem (trunk) of the left bundle branch, (3) concomitant block on the left fascicles or divisions of left bundle branch (divisional or

Address for correspondence: Eduardo Moreyra Jr., MD, FACC, Head of Cardiology Division, Sanatorio Allende, Obispo Oro 42, Córdoba Capital, Argentina, tel: +54-9-3515909614; fax: +54-351-4269212, e-mail: eddie.moreyra@gmail.com 
fascicular CLBBB), or (4) on left Purkinje globally approached, causing sequential biventricular activation with a consequent delay of the electrical activation between the septum and lateral wall of the left ventricle [1,2]. This conduction disorder causes loss of normal ventricular contraction synchronism, which may lead to deterioration of left ventricular function $[2,3]$.

CLBBB has been closely associated with cardiovascular diseases such as hypertension, coronary artery disease, the two previous in combination, valvular heart disease, idiopathic dilated cardiomyopathy, Lev disease, Lenègre disease, and other causes considered miscellaneous $[4,5]$. However, in approximately $12 \%$ of cases, no evidence of organic heart disease is apparent at the time of CLBBB diagnosis [6]. CLBBB may precede the onset of heart disease for years, leading some investigators to consider it a possible precursor to latent cardiomyopathy [2]. Although some studies have suggested that CLBBB may have a benign prognosis [7, 8], most have indicated that CLBBB has poorer prognosis in comparison to normal intraventricular conduction and also compared to right bundle branch block, with a median survival of 5 years from the time of diagnosis $[2,4,5,7,9-12]$. Furthermore, the electrocardiography (ECG) characteristics of CLBBB obscure the application of common criteria for the diagnosis of left ventricular hypertrophy (LVH), myocardial infarction (MI) in the chronic phase, and diseases that cause modifications on the ST-T segment, establishing a need for other studies to assess these heart diseases in the presence of CLBBB [13-17].

The objective of this study was to establish the relationship between the ECG characteristics of CLBBB and structural heart diseases evaluated by transthoracic echocardiogram (TTE). Specifically, the following aspects were evaluated: (1) prevalence of structural heart disease vs. normal heart; (2) ECG criteria for LVH in relation to left ventricular mass index (LVMI) assessed by TTE; (3) validity of the QRS axis and duration to discriminate between normal and reduced left ventricular ejection fraction (LVEF), and (4) sensitivity and specificity of ECG signs described in the literature for the diagnosis of chronic phase of MI.

\section{Methods}

This observational, descriptive, cross-sectional study involved the analysis of ECGs with CLBBB from hospitalized and ambulatory patients at our institution between May 2012 and May 2013. Patients over 18 years of age who had a TTE performed at an interval no longer than 6 months from the diagnostic ECG were included. Those who developed CLBBB during an acute coronary syndrome or $24 \mathrm{~h}$ before death were excluded.

The diagnostic criterion for CLBBB was the combination of QRS complex duration $\geq 120 \mathrm{~ms}$; wide, monophasic, slurred, or notched $\mathrm{R}$ wave recorded slowly in the left leads (I, aVL, V5, and V6); QS or rS pattern in the right precordial leads and; ventricular activation time, intrinsicoid deflection or "R peak time" $\geq 60 \mathrm{~ms}$ in the left precordial leads V5 and V6 [18].

The medical records of the included patients were reviewed to assess cardiovascular risk factors and past medical history. The echocardiographic parameters surveyed were LVEF (normal value $55-75 \%$ ), LVMI (normal value: men $<116 \mathrm{~g} / \mathrm{m}^{2}$, women $<96 \mathrm{~g} / \mathrm{m}^{2}$ ), left atrium volume index (normal value $22 \pm 6 \mathrm{~mL} / \mathrm{m}^{2}$ ), presence of moderate to severe valvular disease, and presence of areas of akinesis or dyskinesis with thinning of the ventricular walls [19]. These parameters were assessed along with clinical background to establish the diagnosis of chronic phase of MI, which were classified based on their location as anterior, inferior, or lateral infarctions. The ECG variables evaluated were QRS electrical axis, QRS duration, and QRS voltage as well as the ECG signs described in the literature for the diagnosis of LVH (9 signs) and chronic phase of MI (8 signs, Tables $3-5$ ).

In the context of CLBBB, an electrical axis of the QRS complex in the frontal plane between $-30^{\circ}$ and $+60^{\circ}$ is considered normal; beyond $-30^{\circ}$ as extremely deviated to the left; between $+60^{\circ}$ and $+90^{\circ}$ deviated to the right; and finally, beyond $+90^{\circ}$ as extremely deviated to the right (paradoxical type of Lepeschkin) [20].

Informed consent was obstained from all patients and the Ethic Committee of the institution approved the study.

\section{Statistical analysis}

Continuous data were expressed as mean ( \pm standard deviation) or median (25-75th percentile), and differences were compared with Student's t test or the Mann-Whitney U test, as appropriate. Discrete data were expressed as percentages and compared using the $\chi^{2}$ test or Fisher's exact test, as appropriate. The area under the receiver operating characteristic curve was used to evaluate the diagnostic accuracy of the ECG criteria for LVH and $\mathrm{MI}$ in the chronic phase. Receiver operating characteristic (ROC) curves were also applied to evaluate the sensitivity and specificity of QRS dura- 
tion and axis deviation for predicting the reduction of LVEF. P values less than 0.05 were considered statistically significant.

\section{Results}

One hundred and one patients met the inclusion criteria, of whom 58 were male. Patients' mean age was $68 \pm 12$ years; $86(85 \%)$ were hypertensive; $42(42 \%)$ suffered from coronary heart disease; 63 (62\%) had dyslipidemia and $31(31 \%)$ were diabetic (Table 1 ).

The QRS duration was $139 \pm 16 \mathrm{~ms}$. The mean electrical axis was $-16.6 \pm 36.6$ degrees. The electrical axis was normal in $59(58 \%)$ patients, deviated to the left in $40(40 \%)$, and deviated to the right in $2(2 \%)$ patients (Table 2$)$.

The mean LVEF was $51.9 \pm 18 \%$, with reduced values in $39 \%$ of patients (Table 2 ). The prevalence of structural heart disease was $90 \%$. Sixty (59\%) patients presented TTE criteria of LVH. The mean LVMI was $105.8 \pm 35.5 \mathrm{~g} / \mathrm{m}^{2}$ in women and $124.4 \pm$ $\pm 39.6 \mathrm{~g} / \mathrm{m}^{2}$ in men. Twelve $(12 \%)$ patients presented moderate or severe valvular heart disease, 3 of them had severe aortic stenosis; 57 (56\%) left atrial enlargement; and $43(42 \%)$ chronic phase infarcts. Only 10 (10\%) patients had normal TTE.

The sensitivity, specificity, positive and negative predictive values of the signs for LVH diagnosis are listed in Table 3. For all these signs, the areas under the ROC curves were less than 0.65 (Fig. 1). No ECG parameter was able to predict the presence of reduced LVEF, since QRS duration $(\mathrm{p}=0.16)$ and left axis deviation $(\mathrm{p}=0.09)$ demonstrated no relation to reduced LVEF. When applying ROC curves to different parameters of electrical axis deviation and QRS duration, electrical axis $<30^{\circ}$ was found to have moderate sensitivity and specificity for detecting reduced LVEF. By contrast, QRS duration > 155 ms demonstrated high specificity and reduced sensitivity (Table 4). Forty-two (42\%) patients had a history of MI confirmed by TTE (Fig. 2). Eight different ECG signs proposed for the diagnosis of $\mathrm{MI}$ in the chronic phases demonstrated similar effectiveness, with high specificity and reduced sensitivity (Table 5).

\section{Discussion}

This study demonstrated that the presence of CLBBB is associated with a high prevalence of structural heart disease (90\%) and that it hinders the implementation of common diagnostic ECG criteria for heart disease. Distinguishing patients
Table 1. Baseline characteristics.

\begin{tabular}{lc}
\hline Number of patients & 101 \\
Male & $58(57 \%)$ \\
Age [years] & $68 \pm 12$ \\
Hypertension & $86(85 \%)$ \\
Diabetes mellitus & $31(31 \%)$ \\
Dyslipidemias & $63(62 \%)$ \\
Smoking history & $35(35 \%)$ \\
Coronary disease & $42(42 \%)$ \\
Heart failure & $26(26 \%)$ \\
Obesity & $35(36 \%)$ \\
Stroke & $10(10 \%)$ \\
\hline
\end{tabular}

Table 2. Electrocardiographic and echocardiographic characteristics.

\begin{tabular}{lc}
\hline Electrocardiographic findings & \\
Sinus rhythm & $95(96 \%)$ \\
Axis [ $\left.{ }^{\circ}\right]$ & $16.63 \pm 36.61$ \\
$\quad$ Normal axis & $59(58 \%)$ \\
Left axis deviation & $40(40 \%)$ \\
Right axis deviation & $2(2 \%)$ \\
$\quad$ Extreme right axis deviation & $0(0 \%)$ \\
QRS duration [ms] & $139 \pm 16$ \\
Left atrial enlargement & $38(38 \%)$ \\
Echocardiographic findings & \\
Left ventricular mass index $\left[\mathrm{g} / \mathrm{m}^{2}\right]:$ & \\
$\quad$ Males & $124.4 \pm 39.7$ \\
Females & $105.8 \pm 35.4$ \\
Left ventricular hypertrophy & $60(59 \%)$ \\
Left atrial volume index $\left[\mathrm{mL} / \mathrm{m}^{2}\right]$ & $31.1 \pm 10.1$ \\
Left atrial enlargement & $57(56 \%)$ \\
Left ventricular ejection fraction $[\%]$ & $51.9 \pm 18.0$ \\
Low ejection fraction & $40(39 \%)$ \\
Regional left ventricular & $42(42 \%)$ \\
contraction defects & $12(12 \%)$ \\
Moderate or severe heart & \\
valve disease & \\
\hline
\end{tabular}

with heart disease from those with normal hearts, diagnosing $\mathrm{LVH}$, and predicting reduced LVEF were not possible. The effectiveness of multiple ECG signs for the diagnosis of chronic phase of MI and LVH was similar, showing high specificity but reduced sensitivity.

The prevalence of CLBBB increases with age, at $0.05 \%$ in patients younger than 30 years, $0.4 \%$ at age $50,2.3 \%$ at 75 , and $5.7 \%$ in patients over 
Table 3. Diagnostic accuracy of electrocardiographic criteria for left ventricular hypertrophy.

\begin{tabular}{|c|c|c|c|c|}
\hline & Sensitivity & Specificity & PPV & NPV \\
\hline $\mathrm{S} V 2+\mathrm{R}$ V6 > $4.5 \mathrm{mV}[14,30]$ & 17 & 85 & 63 & 41 \\
\hline $\mathrm{R}$ aVL $>0.75 \mathrm{mV}[6,14]$ & 27 & 76 & 62 & 41 \\
\hline $\mathrm{S} \mathrm{V} 3+\mathrm{R}$ aVL $>2 \mathrm{mV}$ in women and $>2.8 \mathrm{mV}$ in men [30] & 53 & 46 & 59 & 40 \\
\hline $\mathrm{S} \vee 2>3 \mathrm{mV}[30]$ & 25 & 87 & 75 & 43 \\
\hline $\mathrm{S}$ V3 > $2.5 \mathrm{mV}[30]$ & 23 & 83 & 67 & 43 \\
\hline $\mathrm{S} \vee 1$ or S V2 o S V3 > $3 \mathrm{mV}[7]$ & 30 & 80 & 69 & 44 \\
\hline $\mathrm{R}$ V6 > $2.5 \mathrm{mV}$ [6] & 3 & 99 & 99 & 41 \\
\hline QRS duration > $160 \mathrm{~ms}[14,30]$ & 25 & 85 & 71 & 44 \\
\hline QRS axis < 40 [30] & 50 & 80 & 79 & 52 \\
\hline
\end{tabular}

PPV - positive predictive value; NPV — negative predictive value

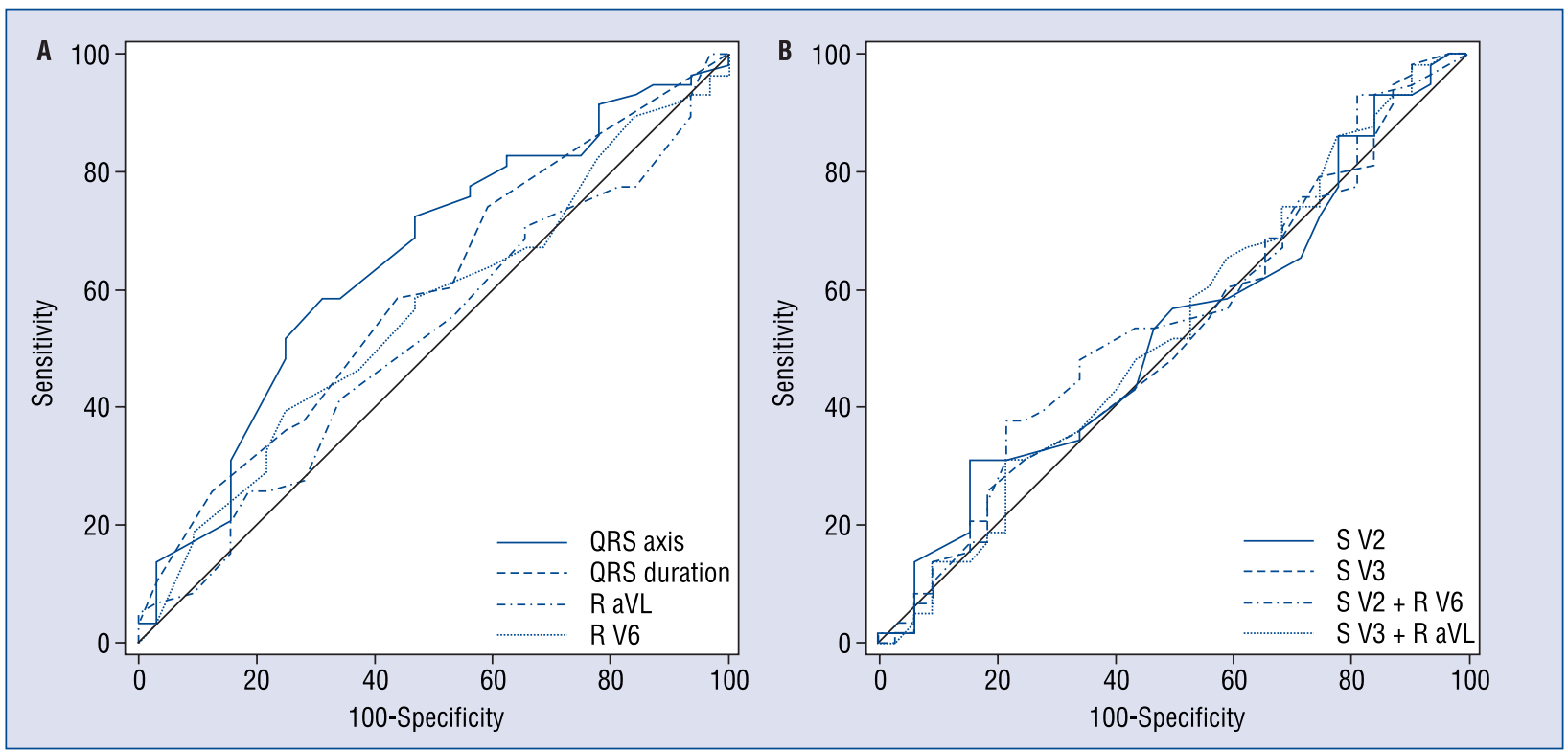

Figure 1. Receiver operating characteristic $(R O C)$ curves for electrocardiogram diagnostic criteria of left ventricular hypertrophy (LVH) in patients with complete left bundle branch block. ROC curve values: QRS duration: 0.597; QRS axis: 0.648; R aVL: 0.515; R V6: 0.588; S V2: 0.527; S V3: 0.516; S V2: + R V6: 0.543; S V3 + R aVL: 0.528; S V2: 0.528 . For all these signs, the areas under the ROC curves were less than 0.65 .

Table 4. Receiver operating characteristic curve analysis of QRS axis and duration in relation to reduced left ventricular ejection fraction.

\begin{tabular}{lcccc}
\hline & Sensitivity & Specificity & PPV & NPV \\
\hline QRS axis $<30^{\circ}$ & 62 & 58 & 69 & 50 \\
QRS duration $>155 \mathrm{~ms}$ & 35 & 88 & 62 & 70 \\
\hline
\end{tabular}

PPV — positive predictive value; NPV — negative predictive value

80 years of age $[21,22]$. The causes of CLBBB are degenerative, mechanical, and/or ischemic, which explains its association with underlying organic heart disease [2, 17, 23]. Autopsy studies have shown a $95 \%$ prevalence of structural heart diseases among patients with CLBBB, similar to 


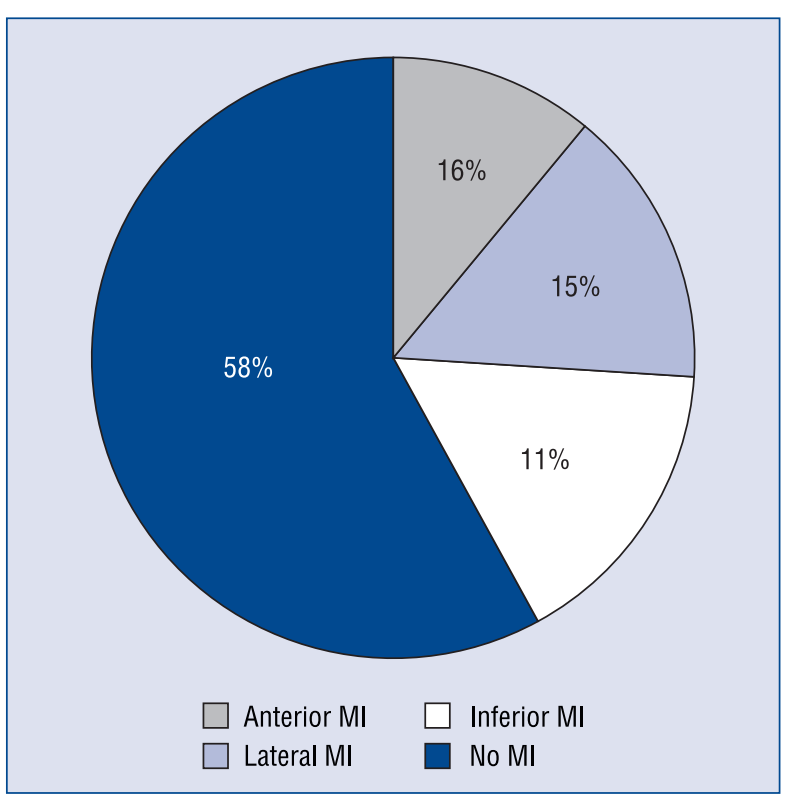

Figure 2. Prevalence and localization of chronic phase myocardial infarction (MI) in patients with complete left bundle branch block.

that found in this study [9]. No ECG sign was useful to distinguish patients with heart disease from those with normal hearts. While this finding might have been due to the small number of patients with normal TTE, to our knowledge no descriptions in the literature allow the accurate distinction of these two groups of patients. Although the presence of CLBBB in hearts without apparent illness, especially in young patients, may have good long-term prognosis, a meticulous and prolonged follow-up is always necessary because CLBBB may be the first sign of a future cardiovascular disease ("latent cardiomyopathy") [2].
The prevalence of LVH documented with TTE was $59 \%$, similar to that of other echocardiographic studies and less than the $90 \%$ prevalence described in anatomical-pathological observations [17, 24]. The identification of LVH in patients with CLBBB has been controversial: some studies have reported correlations between various ECG voltage criteria and CLBBB, while others have not been able to confirm these findings $[14,16,17,24]$. In the present study, none of the criteria were significantly correlated with $\mathrm{LVH}$, and the area under the ROC curve was less than 0.6 in all cases. As in previous studies, we found that the evaluated criteria have reasonable specificity but low sensitivity [14], which could be explained, in part, by the fact that $\mathrm{QRS}$ voltage tends to decrease after the appearance of CLBBB in patients with LVH [9].

Several manuscripts indicate that the presence of extreme left axis deviation, right axis deviation (paradoxical type) and very prolonged QRS complex in patients with CLBBB are markers of poor prognosis [10, 11, 17, 25-27]. These findings led us to hypothesize that both ECG parameters could be useful to detect left ventricular systolic dysfunction. In this series, the average QRS duration was similar to that found in other studies, as was the percentage of patients with extreme QRS axis deviation to the left, which was approximately $60 \%$ [17]. Nevertheless, neither of these parameters correlated with reduction of LVEF. One possible explanation for QRS prolongation and left axis deviation being signs of poor prognosis while having no relation to reduced LVEF may be that both signs primarily reflect disease of the conduction system rather than damage to the myocardium [17]. This explanation is supported by the findings of Spurrel et al. [28] and Dhingra et al. [3] showing that left

Table 5. Diagnostic accuracy of electrocardiographic criteria for myocardial infarction in the chronic phase.

\begin{tabular}{|c|c|c|c|c|}
\hline & Sensitivity & Specificity & PPV & NPV \\
\hline $\begin{array}{l}\text { Notching }>40 \mathrm{~ms} \text { in the ascending limb of the S wave } \\
\text { in leads V3 to V5 (Cabrera sign) }[15,29]\end{array}$ & 14 & 93 & 25 & 87 \\
\hline QS pattern from leads V1 to V4 [15] & 11 & 82 & 6 & 90 \\
\hline $\mathrm{R}$ wave regression from leads $\mathrm{V} 1$ to $\mathrm{V} 4[15]$ & 14 & 94 & 29 & 83 \\
\hline $\begin{array}{l}\text { Notching }>40 \mathrm{~ms} \text { in the ascending limb of the } \mathrm{R} \text { wave in lead I, } \\
\text { aVL, V5 and V6 (Chapman sign) }[15,29]\end{array}$ & 7 & 84 & 7 & 84 \\
\hline RS pattern with terminal S wave $>40$ ms in leads V5 to V6 [15] & 25 & 70 & 10 & 87 \\
\hline Presence of $\mathrm{Q}$ waves in I, aVL, V5 and V6 [17] & 8 & 98 & 33 & 89 \\
\hline $\begin{array}{l}\text { Notching }>40 \mathrm{~ms} \text { in the ascending limb of the R wave } \\
\text { in lead of II, III, and aVF [18] }\end{array}$ & 10 & 86 & 7 & 89 \\
\hline Presence of $\mathrm{Q}$ waves in two inferior leads (II, III, or aVF) [18] & 9 & 80 & 5 & 89 \\
\hline
\end{tabular}

PPV — positive predictive value; NPV — negative predictive value 
axis deviation and QRS prolongation in patients with CLBBB were related to greater prolongation of the PR, AH, and HV intervals and atrial and atrioventricular refractory periods which, in turn, was associated with increased mortality.

A significant percentage of patients with CLBBB had coronary artery disease. More than 57 signs have been proposed for the diagnosis of chronic phase of MI in patients with CLBBB $[15,29]$. In the present study, none of the 8 most common diagnostic criteria had a high diagnostic efficiency or was superior to the others. All were characterized by a high specificity and reduced sensitivity, consistent with the concept that the CLBBB obscures the diagnosis of evolved infarcts, regardless of their location $[15,17]$.

\section{Limitations of the study}

The limitations of this study should be acknowledged. The presence of heart disease was evaluated only with TTE and not with other methods that would have provided complementary information. The diagnosis of chronic phase of MI and its location was based on medical history and echocardiographic findings, but no angiographic corroboration was available in many cases. Furthermore, the sample of patients included represents a population of an elevated average age, which can greatly influence the conclusions. Finally, the statistical power to establish associations was limited owing to the low number of patients included.

\section{Conclusions}

The prevalence of cardiac structural disease is elevated in patients with CLBBB. Its presence hinders the application of common ECG criteria for the diagnosis of $\mathrm{LVH}$, reduced LVEF, and the presence of chronic phase of MI. No ECG characteristics could distinguish patients with normal hearts from those with structural heart disease. ECG criteria for the diagnosis of $\mathrm{LVH}$ and chronic phase of MI have low sensitivity, but high specificity which is valuable when present but cannot discard these conditions when absent.

\section{Conflict of interest: None declared}

\section{References}

1. Andersson LG, Wu KC, Wieslander B et al. Left ventricular mechanical dyssynchrony by cardiac magnetic resonance is greater in patients with strict vs nonstrict electrocardiogram criteria for left bundle-branch block. Am Heart J, 2013; 165: 956-963.
2. Breithardt G, Breithardt OA. Left bundle branch block, an oldnew entity. J Cardiovasc Transl Res, 2012; 5: 107-116.

3. Dhingra R, Pencina MJ, Wang TJ et al. Electrocardiographic QRS duration and the risk of congestive heart failure: The Framingham Heart Study. Hypertension, 2006; 47: 861-867.

4. Lewinter C, Torp-Pedersen C, Cleland JG, Køber L. Right and left bundle branch block as predictors of long-term mortality following myocardial infarction. Eur J Heart Fail, 2011; 13: 1349-1354.

5. Kumar V, Venkataraman R, Aljaroudi W et al. Implications of left bundle branch block in patient treatment. Am J Cardiol, 2013; 111: 291-300.

6. Mirvis DM, Goldberger AL. Electrocardiography. In: Bonow RO, Mann DL, Zipes DP, Libby P eds. Braunwald's heart disease: A textbook of cardiovascular medicine. 9th Ed. Elsevier Saunders, Philadelphia 2012: 126-167.

7. Fahy GJ, Pinski SL, Miller DP et al. Natural history of isolated bundle-branch block. Am J Cardiol, 1996; 77: 1185-1190.

8. Francia P, Balla C, Paneni F, Volpe M. Left bundle-branch block pathophysiology, prognosis, and clinical management. Clin Cardiol, 2007; 30: 110-115.

9. Zmyslinski RW, Richeson JF, Akiyama T. Left ventricular hypertrophy in presence of complete left bundle-branch block. $\mathrm{Br}$ Heart J, 1980; 43: 170-175.

10. Brenyo A, Zaręba W. Prognostic significance of QRS duration and morphology. Cardiol J, 2011; 18: 8-17.

11. Badheka AO, Singh V, Patel NJ et al. QRS duration on electrocardiography and cardiovascular mortality (from the National Health and Nutrition Examination Survey-III). Am J Cardiol, 2013; 112: 671-677.

12. Zhang ZM, Rautaharju PM, Soliman EZ et al. Mortality risk associated with bundle branch blocks and related repolarization abnormalities (from the Women's Health Initiative [WHI]). Am J Cardiol, 2012; 110: 1489-1495.

13. Fragola PV, Autore C, Ruscitti G, Picelli A, Cannata D. Electrocardiographic diagnosis of left ventricular hypertrophy in the presence of left bundle branch block: A wasted effort. Int J Cardiol, 1990; 28: 215-221.

14. Baranowski R, Małek L, Prokopowicz D, Spiewak M, Miśko J. Electrocardiographic diagnosis of the left ventricular hypertrophy in patients with left bundle branch block: Is it necessary to verify old criteria? Cardiol J, 2012; 19: 591-596.

15. Sgarbossa EB, Pinski SL, Barbagelata A et al. Electrocardiographic diagnosis of evolving acute myocardial infarction in the presence of left bundle-branch block. GUSTO-1 (Global Utilization of Streptokinase and Tissue Plasminogen Activator for Occluded Coronary Arteries) Investigators. N Engl J Med, 1996; 334: 481-487.

16. Upshaw CB Jr. Seeing through the maze of complete left bundle branch block. J Med Assoc Ga, 1993; 82: 593-599.

17. Havelda CJ, Sohi GS, Flowers NC, Horan LG. The pathologic correlates of the electrocardiogram: complete left bundle branch block. Circulation, 1982; 65: 445-451.

18. Surawicz B, Childers R, Deal BJ et al. AHA/ACCF/HRS recommendations for the standardization and interpretation of the electrocardiogram: Part III. Intraventricular conduction disturbances: A scientific statement from the American Heart Association Electrocardiography and Arrhythmias Committee, Council on Clinical Cardiology; the American College of Cardiology Foundation; and the Heart Rhythm Society. Endorsed by the International Society for Computerized Electrocardiology. J Am Coll Cardiol, 2009; 53: 976-981. 
19. Lang RM, Bierig M, Devereux RB et al. Recommendations for chamber quantification: a report from the American Society of Echocardiography's Guidelines and Standards Committee and the Chamber Quantification Writing Group, developed in conjunction with the European Association of Echocardiography, a branch of the European Society of Cardiology. J Am Soc Echocardiogr, 2005; 18: 1440-1463.

20. Pérez Riera AR, Uchida AH, Filho CF et al. Significance of vectorcardiogram in the cardiological diagnosis of the 21st century. Clin Cardiol, 2007; 30: 319-323.

21. Ostrander LD Jr, Brandt RL, Kjelsberg MO, Epstein FH. Electrocardiographic findings among the adult population of a total natural community, Tecumseh, Michigan. Circulation, 1965; 31: 888-898.

22. Eriksson P, Hansson PO, Eriksson H, Dellborg M. Bundle-branch block in a general male population: the study of men born 1913. Circulation, 1998; 98: 2494-2500.

23. SchneiderJF, Thomas HEJr, Kreger BE, McNamara PM, KannelWB. Newly acquired left bundle-branch block: The Framingham study. Ann Intern Med, 1979; 90: 303-310.
24. Petersen GV, Tikoff G. Left bundle branch block and left ventricular hypertrophy: Electrocardiographic-pathologic correlations. Chest, 1971; 59: 174-177.

25. Miller WL, Hodge DO, Hammill SC. Association of uncomplicated electrocardiographic conduction blocks with subsequent cardiac morbidity in a community-based population (Olmsted County, Minnesota). Am J Cardiol, 2008; 101: 102-106.

26. Dhingra RC, Amat-Y-Leon F, Wyndham C, Sridhar SS, Wu D, Rosen KM. Significance of left axis deviation in patients with chronic left bundle branch block. Am J Cardiol, 1978; 42: 551-556.

27. Patel PJ, Verdino RJ. Usefulness of QRS axis change to predict mortality in patients with left bundle branch block. Am J Cardiol, 2013; 112: 390-394.

28. Spurrell RA, Krikler DM, Sowton E. Apparently benign left bundle branch block. Proc R Soc Med, 1972; 65: 876-877.

29. Deveci B, Ozeke O, Ozlu MF et al. Comparison of the electrocardiographic features of complete left bundle branch block in patients with ischemic and nonischemic left ventricular dysfunction. Eur J Heart Fail, 2007; 7: 26-32.

30. Flowers NC. Left bundle branch block: A continuously evolving concept. J Am Coll Cardiol, 1987; 9: 684-697. 